EUROPEAN ORGANIZATION FOR NUCLEAR RESEARCH

European Laboratory for Particle Physics

arge Hadron Collider Project

LHC Project Report 510

\title{
A LARGE-SCALE TEST FACILITY FOR HEAT LOAD MEASUREMENTS DOWN TO $1.9 \mathrm{~K}$
}

\author{
L. Dufay, C. Policella, J.-M. Rieubland and G. Vandoni
}

\begin{abstract}
Laboratory-scale tests aimed at minimizing the thermal loads of the LHC magnet cryostat have gone along with the development of the various mechanical components. For final validation of the industrial design with respect to heat inleaks between large surfaces at different temperatures, a full-scale test cryostat has been constructed. The facility reproduces the same pattern of temperature levels as the LHC dipole cryostat, avoiding the heat inleaks from local components like supports and feedthroughs and carefully minimizing fringe effects due to the truncated geometry of the facility with respect to the LHC cryostats serial layout.

Thermal loads to the actively cooled radiation screen, operated between $50 \mathrm{~K}$ and $65 \mathrm{~K}$, are measured by enthalpy difference along its length. At $1.9 \mathrm{~K}$, the loads are obtained from the temperature difference across a superfluid helium exchanger. On the beam screen, the electrical power needed to stabilize the temperature at $20 \mathrm{~K}$ yields a direct reading of the heat losses. Precise in-situ calibration is achieved by subcooling the thermal screen, thereby zeroing radiative heat loads. Minimizing fringe effects has been rewarded by a high precision measurement, yielding one of the more accurate quantifications to date of an industrial application of MLI. The influence of possible openings in the thermal screen is monitored both at the $1.9 \mathrm{~K}$ bath and with a radiation sensitive bolometer.
\end{abstract}

LHC Division

Presented at the 2001 Cryogenic Engineering Conference and International Cryogenic Materials Conference CEC/ICMC 2001

16-20 July 2001, Madison, Wisconsin, USA

\footnotetext{
Administrative Secretariat

LHC Division

CERN

CH - 1211 Geneva 23

Switzerland

Geneva, 19 October 2001
} 


\title{
A LARGE-SCALE TEST FACILITY FOR HEAT LOAD MEASUREMENTS DOWN TO $1.9 \mathrm{~K}$
}

\author{
L.Dufay, C.Policella, J.-M.Rieubland, G.Vandoni \\ LHC Division, CERN, Geneva, Switzerland
}

\begin{abstract}
Laboratory-scale tests aimed at minimizing the thermal loads of the LHC magnet cryostat have gone along with the development of the various mechanical components. For final validation of the industrial design with respect to heat inleaks between large surfaces at different temperatures, a full-scale test cryostat has been constructed. The facility reproduces the same pattern of temperature levels as the LHC dipole cryostat, avoiding the heat inleaks from local components like supports and feedthroughs and carefully minimizing fringe effects due to the truncated geometry of the facility with respect to the LHC cryostats serial layout.

Thermal loads to the actively cooled radiation screen, operated between $50 \mathrm{~K}$ and $65 \mathrm{~K}$, are measured by enthalpy difference along its length. At $1.9 \mathrm{~K}$, the loads are obtained from the temperature difference across a superfluid helium exchanger. On the beam screen [1], the electrical power needed to stabilize the temperature at $20 \mathrm{~K}$ yields a direct reading of the heat losses. Precise in-situ calibration is achieved by subcooling the thermal screen, thereby zeroing radiative heat loads. Minimizing fringe effects has been rewarded by a high precision measurement, yielding one of the more accurate quantifications to date of an industrial application of MLI. The influence of possible openings in the thermal screen is monitored both at the $1.9 \mathrm{~K}$ bath and with a radiation sensitive bolometer.
\end{abstract}

\section{DESIGN AND OPERATION OF THE FACILITY}

The facility is designed as a thermal replica of the LHC dipole cryostat with respect to purely radiative heat loads. Dimensions are identical to the LHC dipole cryostat [2].

FIG 1 illustrates the PI diagram of the facility. It is equipped with 35 thermometers and 5 flowmeters in total, the essential devices being doubled for redundancy. A feed-box and a return-box, vehiculating the service piping and minimizing the fringe radiative heat loads originating from a truncated geometry, close the two extremities of the $15 \mathrm{~m}$ long, $1 \mathrm{~m}$ diameter vacuum vessel. The central part of the vacuum vessel contains a $2 \mathrm{~mm}$ thick thermal screen of $99.5 \% \mathrm{Al}, 15 \mathrm{~m}$ long and $950 \mathrm{~mm}$ in diameter, actively cooled by gaseous helium flowing in a pipe into the thermal screen extrusion. Both extremities of the screen are closed by a circular plate of polished Al-alloy, protected by MLI. The thermal screen surrounds a second cylinder of pure Al (99.99\%), $2.5 \mathrm{~mm}$ thick, $15 \mathrm{~m}$ long and with a diameter of $750 \mathrm{~mm}$, simulating a cold-mass, sustained by two columnar composite 


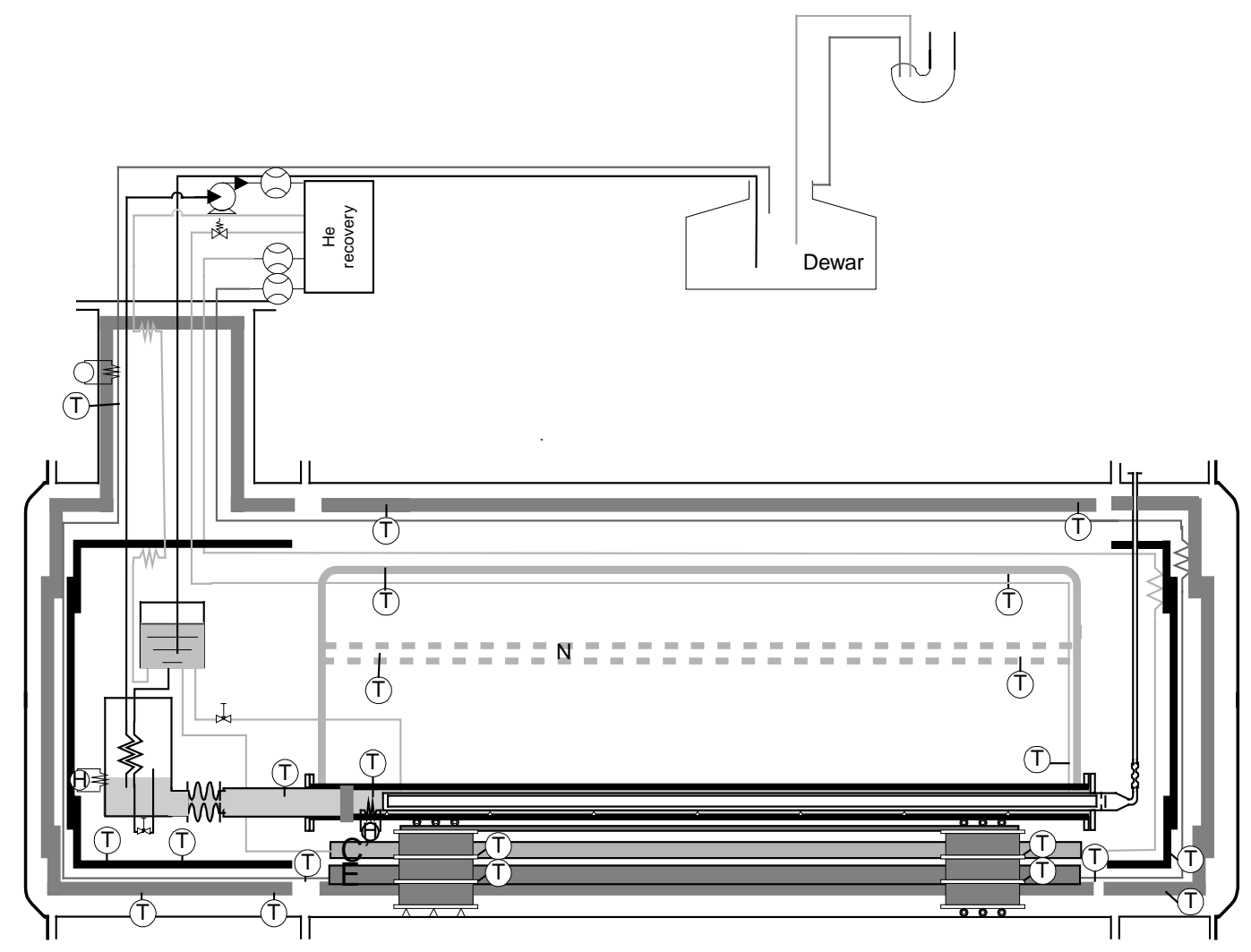

FIGURE 1. Process and Instrumentation Diagram of the facility.

support posts, instead of the three of the LHC dipole cold mass. Also the pseudo cold-mass is closed at its two extremities, to limit heat leaks from the end-boxes. Along the pseudo cold-mass, a point-welded cylindrical ear simulates the auxiliary bus-bar tube (line $\mathrm{N}$ in LHC) equipped with 2 thermometers and remaining at $3 \mathrm{~K}$ during all measurements.

The pseudo cold-mass is welded along all its length on a cylindrical (internal diameter $80 \mathrm{~mm}$, external diameter $90 \mathrm{~mm}$ ) pressurized superfluid helium header in Al-alloy, which is cooled by a cylindrical copper heat exchanger (diameter $35 \mathrm{~mm}$ and length $100 \mathrm{~mm}$ ) connected to a saturated helium II bath. This "cold finger" plays the role of a heat-flow measuring device (heatmeter). The lowest of the two stainless steel plates constituting the heat intercepts of each support post are fixed to the thermal screen, the upper ones are cooled by a separate liquid helium pipe, wound and brazed onto the plate. Heat load from the supports to the pseudo cold-mass, already reduced with respect to the LHC due to the small weight of the hollow Al cylinder $(\sim 150 \mathrm{~kg})$, is further minimized by composite spacers, covered with Teflon, which are mounted on the upper extremity of the support posts. The $80 \mathrm{~mm}$ pressurized helium II tube houses a second tube, of the dimensions of a LHC cold bore, which is vacuum pumped through a radiation-screened tube, to limit external heat input. A beam screen, equipped with a resistive heater and several thermometers along its whole length, is housed into this cold bore.

A 20001 dewar, maintained at constant pressure, supplies the cold helium for the operation of the facility. Gaseous helium is heated to the desired operation temperature of the thermal screen, before being supplied to the screen and the supports through line E. Liquid helium is transferred to a phase separator from which it feeds the feed-box screens, the supports cooling line $\mathrm{C}^{\prime}$, and fills up a saturated helium II vessel through an expansion valve. A fourth line from the phase separator supplies the $15 \mathrm{~m}$ long pressurized helium II header. During cooldown, a narrow pipe is used to circulate helium into the pressurized helium II header; this pipe is then isolated during normal operation. 
The MLI blankets submitted to thermal evaluation surround the thermal screen and the pseudo cold-mass. Thermal loads to the screen are measured by enthalpy balance:

$$
\dot{Q}=\dot{m} C_{p} \Delta T
$$

The gas flow in line $\mathrm{E}$ is measured with a mass flowmeter, and the gas temperature is sensored before and after the screen, the temperature difference yielding the enthalpy increase of the gas. Since all the terms of the equation are known or measurable, no calibration is necessary. The heat load from the support posts, however, is included into this measurement, and has therefore to be subtracted from the result. On the cold mass, the heat flow is evaluated by the temperature difference between the pressurized and the saturated helium II baths, measured across the copper cold finger. Below the $\lambda$-transition, this temperature difference is essentially determined by the Kapitza impedance, yielding a high sensitivity measurement of the heat evacuated through the cold finger ("Kapitza heatmeter"[3]). To control shifts in time of the Kapitza impedance, the device is frequently recalibrated in-situ. This is performed by cooling the thermal screen to $\sim 20 \mathrm{~K}$, to minimize the radiative heat load to the cold mass, and sending a known heating power into the pressurized bath. The power can also be adjusted to obtain exactly the same temperature difference as measured with a warm screen. This procedure ensures that parasitic heat leaks on the bath are not unduly added to the radiative heat flow through the MLI. Furthermore, a calibration of the heat-exchanger in a stand-alone configuration is also performed ex-situ in a separate configuration obtained by joining feed-box and return-box without the central part of the cryostat. Residual heat leaks can be identified and minimized by comparing the in-situ and the ex-situ calibrations.

The heat load from the beam screen is assessed by measuring the power on the resistive heater, at stable temperature. Under steady-state conditions, the power output to the heater is exactly compensated by the losses to the cold bore, provided that the beam screen is perfectly insulated towards all parasitic heat flow paths.

\section{RESULTS AND DISCUSSION}

The contribution to the thermal loads both at the thermal screen and the pseudo coldmass by the support posts is known from previous measurements [4] and calculation. We considered a heat load to the thermal screen of $7.6 \mathrm{~W}$ per support in normal conditions (the first run, though, was performed without radiation screening internally to the post, in this case we estimate $9.5 \pm 1 \mathrm{~W}$ per support), with a negligible dependence on thermal screen temperature. The uncertainty of $\pm 1 \mathrm{~W}$ per support constitutes the error on the total heat loss at the thermal screen. The heat load from the supports to the pseudo cold-mass amounts to $20 \mathrm{~mW}$ per support at $60 \mathrm{~K}$ and $14 \mathrm{~mW}$ at $20 \mathrm{~K}$. The latter contribution is automatically included into the zero-point calibration as a residual heat leak, leaving the total estimated

TABLE 1. Characteristics of the two tested MLI samples, delivered by two different suppliers.

\begin{tabular}{|c|c|c|c|c|}
\hline & Spacer & Reflector & Boundary layer & Closing \\
\hline $\begin{array}{c}\text { Type } \\
\text { A }\end{array}$ & $\begin{array}{l}\text { Polyester net } \\
\quad \text { (tulle) }\end{array}$ & $\begin{array}{l}6 \mu \mathrm{m} \text { polyester }(\mathrm{PETP}), \\
\text { double aluminized, } 400 \AA \\
\text { aluminium coating }\end{array}$ & $\begin{array}{l}12 \mu \mathrm{m} \text { polyester film }(\mathrm{PETP}) \text {, double } \\
\text { face aluminized } 400 \AA \text {, with reinforcing } \\
\text { polyester net on the inner side }\end{array}$ & $\begin{array}{l}\text { Velcro, } \\
\text { edge-to- } \\
\text { edge }\end{array}$ \\
\hline $\begin{array}{c}\text { Type } \\
\text { B }\end{array}$ & $\begin{array}{l}\text { Polyester net } \\
\quad \text { (tulle) }\end{array}$ & $\begin{array}{l}6 \mu \mathrm{m} \text { polyester }(\mathrm{PETP}), \\
\text { double aluminized, } 400 \AA \\
\text { aluminium coating }\end{array}$ & $\begin{array}{l}6 \mu \mathrm{m} \text { polyester film }(\mathrm{PETP}) \text {, double } \\
\text { face aluminized } 700 \AA \text {, with reinforcing } \\
\text { polyester net on the inner side }\end{array}$ & $\begin{array}{l}\text { Velcro, } \\
\text { edge-to- } \\
\text { edge }\end{array}$ \\
\hline
\end{tabular}


TABLE 2. Heat inleaks for different thermal screen temperatures. *In this run, no MLI is mounted around the pseudo cold-mass. ${ }^{\ddagger}$ These values have not been measured, they are estimated from calculation [4]. Residual gas pressure is maintained below $5.010^{-5} \mathrm{~Pa}$.

\begin{tabular}{|c|c|c|c|c|c|c|}
\hline \multirow{3}{*}{$\begin{array}{c}\text { Thermal screen } \\
\text { temperature } \\
\qquad[\mathrm{K}]\end{array}$} & \multicolumn{3}{|c|}{ Heat inleaks to thermal screen } & \multicolumn{3}{|c|}{ Heat inleaks to cold mass } \\
\hline & Total & $\begin{array}{c}\text { Support } \\
\text { posts }\end{array}$ & MLI & Total & $\begin{array}{l}\text { Support } \\
\text { posts }^{\#}\end{array}$ & MLI \\
\hline & {$[\mathrm{W}]$} & [W] & {$\left[\mathrm{W} / \mathrm{m}^{2}\right]$} & {$[\mathrm{mW}]$} & {$[\mathrm{mW}]$} & {$\left[\mathrm{mW} / \mathrm{m}^{2}\right]$} \\
\hline \multicolumn{7}{|l|}{ Type A MLI* } \\
\hline 59.5 & 37.6 & $19^{\ddagger}$ & 0.52 & 129 & 13 & 4.3 \\
\hline 78.5 & 36.7 & $19^{\ddagger}$ & 0.47 & 508 & 13 & 18.5 \\
\hline \multicolumn{7}{|l|}{ Type A MLI } \\
\hline 50.1 & 39.1 & 15.2 & 0.63 & 99 & 12 & 3.2 \\
\hline 57.4 & 36.3 & 15.2 & 0.56 & 171 & 12 & 5.9 \\
\hline 68.3 & 32.5 & 15.2 & 0.46 & 352 & 12 & 12.7 \\
\hline \multicolumn{7}{|l|}{ Type B MLI } \\
\hline 52.6 & 42.9 & 15.2 & 0.73 & 141 & 12 & 4.8 \\
\hline 70.9 & 40.5 & 15.2 & 0.67 & 451 & 12 & 16.4 \\
\hline 72.9 & 39.6 & 15.2 & 0.64 & 459 & 12 & 16.7 \\
\hline
\end{tabular}

heat flow from both the supports to the $1.9 \mathrm{~K}$ cold-mass to be equal to $12 \mathrm{~mW}$. The losses on the cold mass can be assessed within $30 \mathrm{~mW}$, which corresponds to the error in the reading of the two Carbon resistor thermometers of the Kapitza heatmeter.

The characteristics of the two types of MLI, from two different suppliers, are displayed in TABLE 1 . Nominally, they differ only in the weight and aluminization of the boundary layers, and in the dimension of the mounted blanket, slightly larger for type A.

A debugging measurement run was performed without MLI on the pseudo cold-mass, which was then simply mechanically polished. In subsequent runs, the thermal screen was equipped with two blankets of 15 layers MLI each, with Velcro closing all along their length, whereas the pseudo cold-mass was protected by one blanket of 10 layers MLI.

TABLE 2 displays the measured heat losses at different temperatures of the thermal screen. TABLE 3 shows the measured heat losses under degraded vacuum conditions. Degradation of the vacuum was obtained by stopping the active pumping and introducing

TABLE 3. Heat inleaks for vacuum degraded with $\mathrm{He}$, as a function of He gas pressure. ${ }^{\&}$ These data have been taken under strong oscillations of the residual vacuum (see explanations in the text).

\begin{tabular}{|c|c|c|c|c|c|c|c|}
\hline \multirow[b]{2}{*}{$\begin{array}{c}\text { Thermal screen } \\
\text { temperature } \\
{[\mathrm{K}]}\end{array}$} & \multicolumn{3}{|c|}{ Heat inleaks to thermal screen } & \multicolumn{3}{|c|}{ Heat inleaks to cold mass } & \multirow[b]{2}{*}{$\begin{array}{c}\text { Residual gas } \\
\text { pressure, } \mathrm{He} \\
{[\mathrm{Pa}]}\end{array}$} \\
\hline & $\begin{array}{l}\text { Total } \\
\text { [W] }\end{array}$ & $\begin{array}{l}\text { Support } \\
\text { posts } \\
\text { [W] }\end{array}$ & $\begin{array}{c}\text { MLI } \\
{\left[\mathrm{W} / \mathrm{m}^{2}\right]}\end{array}$ & $\begin{array}{l}\text { Total } \\
{[\mathrm{mW}]}\end{array}$ & $\begin{array}{l}\text { Support } \\
\text { posts } \\
{[\mathrm{mW}]}\end{array}$ & $\begin{array}{c}\text { MLI } \\
{\left[\mathrm{mW} / \mathrm{m}^{2}\right]}\end{array}$ & \\
\hline \multicolumn{8}{|l|}{ Type A MLI } \\
\hline 49.4 & 37.2 & 15.2 & 0.58 & 306 & 12 & 11.0 & $1.85 \cdot 10^{-3}$ \\
\hline 49.4 & 37.4 & 15.2 & 0.59 & 669 & 12 & 24.5 & $4.35 \cdot 10^{-3}$ \\
\hline 49.3 & 37.5 & 15.2 & 0.59 & 921 & 12 & 33.9 & $5.50 \cdot 10^{-3}$ \\
\hline \multicolumn{8}{|l|}{ Type B MLI } \\
\hline 49.6 & 43.2 & 15.2 & 0.74 & 390 & 12 & 14.1 & $1.40 \cdot 10^{-3}$ \\
\hline${ }^{\&} 50.8$ & 46.0 & 15.2 & 0.82 & 655 & 12 & 24.0 & $1.60 \cdot 10^{-3}$ \\
\hline 44.1 & 41.5 & 15.2 & 0.69 & 1231 & 12 & 45.5 & $3.60 \cdot 10^{-3}$ \\
\hline
\end{tabular}


He gas into the vessel. Two cold-filament vacuum gauges, located respectively at the feedbox and at the return box, monitor the increase in pressure. The insulation vacuum is then reduced to the desired value by shortly switching on the pumping group.

The gauges have been calibrated with respect to a spinning rotor gauge to compensate for the different ionization probability for $\mathrm{He}$ and $\mathrm{N}_{2}$; the values shown in the table are corrected for this effect above $5 \cdot 10^{-5} \mathrm{~Pa}$, i.e., when He constitutes the major component of the residual gas. During one of the measurements of MLI type B, oscillations of $2 \cdot 10^{-4} \mathrm{~Pa}$ in the residual pressure have appeared, and in this situation, thermoacoustic oscillations of an amplitude of $13 \mathrm{kPa}$ were visible on the pressure in the return tube of the superfluid helium saturated bath. The facility does not sustain a residual pressure higher than $5 \cdot 10^{-3} \mathrm{~Pa}$, because the losses on the Kapitza exchanger become too elevated.

Heat inleaks to the thermal screen remain below $0.7 \mathrm{~W} / \mathrm{m}^{2}$ for both types of MLI, a value approaching the minimum heat load from an "ideal" MLI system [5] for 30 layers and a layer density of $45 \mathrm{~cm}^{-1}$. On one hand, this value can be ascribed to the very precise dimensioning of the blankets and the installation technique guaranteed by the use of Velcro to close the blankets, which permits a level of performance of MLI very close to ideal. On the other hand, it is the result of the particular care devoted to reducing fringe effects and residual heat leaks, to ensure that the effect of penetrations and gaps is negligible compared to the MLI heat leak. A slight but systematic dependence of thermal losses from the cold boundary temperature is visible, whose origin can only be justified by a so far unexplained residual heat effect ${ }^{1}$. Not surpringly, no sizeable dependence on the losses of a degraded vacuum is visible (FIG 2), since the losses in this temperature range are dominated by radiation.

Heat inleaks to the cold mass measured at different warm boundary temperatures can be compared with less than $10 \%$ inaccuracy by applying a scaling in $\mathrm{T}^{4}$ [5]. As well known from literature, it appears that a mechanically polished aluminium surface constitutes a

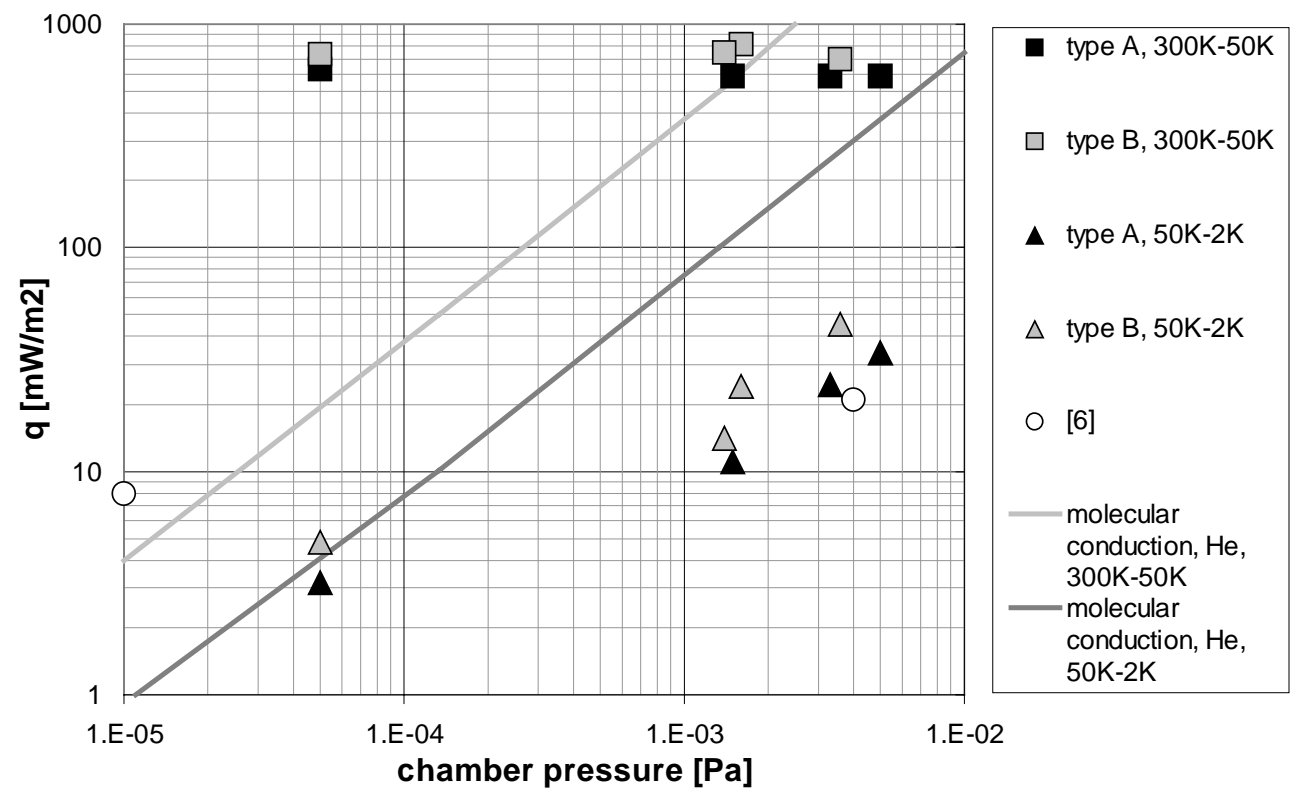

FIGURE 2. Heat inleak across MLI as a function of helium residual pressure. The lines illustrate the heat tranfer by purely molecular conduction for boundary temperatures $300 \mathrm{~K}$ to $50 \mathrm{~K}$ and $50 \mathrm{~K}$ to $2 \mathrm{~K}$.

\footnotetext{
${ }^{1}$ Actually, this effect is not a radiative one, since neither the dominance of the warm boundary temperature on radiation heat exchange $\left(T_{h}{ }^{4}-T_{c}{ }^{4}\right)$ nor an inclusion of the very small temperature dependence of emissivity (yielding a $T^{4.67}$ effect [5]) justify the approximately linear dependence on $\left(T_{h}-T_{c}\right)$. Also the heat loss from the support posts, which has both a radiative and a conductive component between $300 \mathrm{~K}$ and $50 \mathrm{~K}$, depends only very slightly on the cold boundary, giving no quantitative explanation to the observed dependence.
} 
more effective radiation screening than MLI at low boundary temperature, where solid conduction through the MLI spacers determines the losses [6].

The $\mathrm{T}^{4}$ scaling to $77 \mathrm{~K}$ allows easy comparison with "ideal" insulation blanket predictions by T.Nast [5]. As for the thermal screen, the losses on the pseudo cold-mass at low vacuum approach the optimal values reported for an ideal blanket, for the same number of layers and the same maximal density $\left(18-20 \mathrm{~mW} / \mathrm{m}^{2}\right.$ at $\left.77 \mathrm{~K}\right)$. In molecular conduction regime, the heat flux between the thermal screen and the outer layer of MLI depends on pressure, temperature difference, and the nature of the gas [8]:

$$
\dot{q}_{m c}=\alpha \Omega p\left(T_{2}-T_{1}\right) .
$$

where $\alpha$ is the accommodation coefficient and $\Omega$ a factor depending on temperature, molar mass and the $\gamma$ factor of the gas. This dependence is shown on FIG 2 for boundary temperatures $300 \mathrm{~K}-50 \mathrm{~K}$ and $50 \mathrm{~K}-2 \mathrm{~K}$. At cold boundaries, molecular conduction starts dominating upon radiation when the residual pressure exceeds $5 \cdot 10^{-4} \mathrm{~Pa}$, above this pressure MLI performs better than an aluminized surface by limiting the conduction in the residual gas.

Previous measurements performed at CERN on the same type of MLI (double aluminized $400 \AA$, single polyester net spacer, same number of layers) at $77 \mathrm{~K}$ warm boundary, yield a heat flux of $45 \mathrm{~mW} / \mathrm{m}^{2}$ at high vacuum and $120 \mathrm{~mW} / \mathrm{m}^{2}$ at $4 \cdot 10^{-3} \mathrm{~Pa}$ [7]. Applying a fourth-power law in temperature, these values scale to $8 \mathrm{~mW} / \mathrm{m}^{2}$ and 21 $\mathrm{mW} / \mathrm{m}^{2}$ at $50 \mathrm{~K}$. At low residual vacuum, our measurements yield the lowest values, whereas with increasing residual pressure, we measure higher values than in former measurements.

Heat inleaks from the beam screen to the He bath are measured for two configurations of a supporting system for the beam screen [9]. In a first run, a $15.63 \mathrm{~m}$ long beam-screen is installed into the cold mass without any supports. Random contact points occur between the pipe and the cold bore. In a second run, a $11.4 \mathrm{~m}$ long beam-screen is installed into the cold mass with bronze sliding rings as supports, positioned every $0.5 \mathrm{~m}$. FIG 3 displays the temperature profile along the screen for increasing heating power density, for both
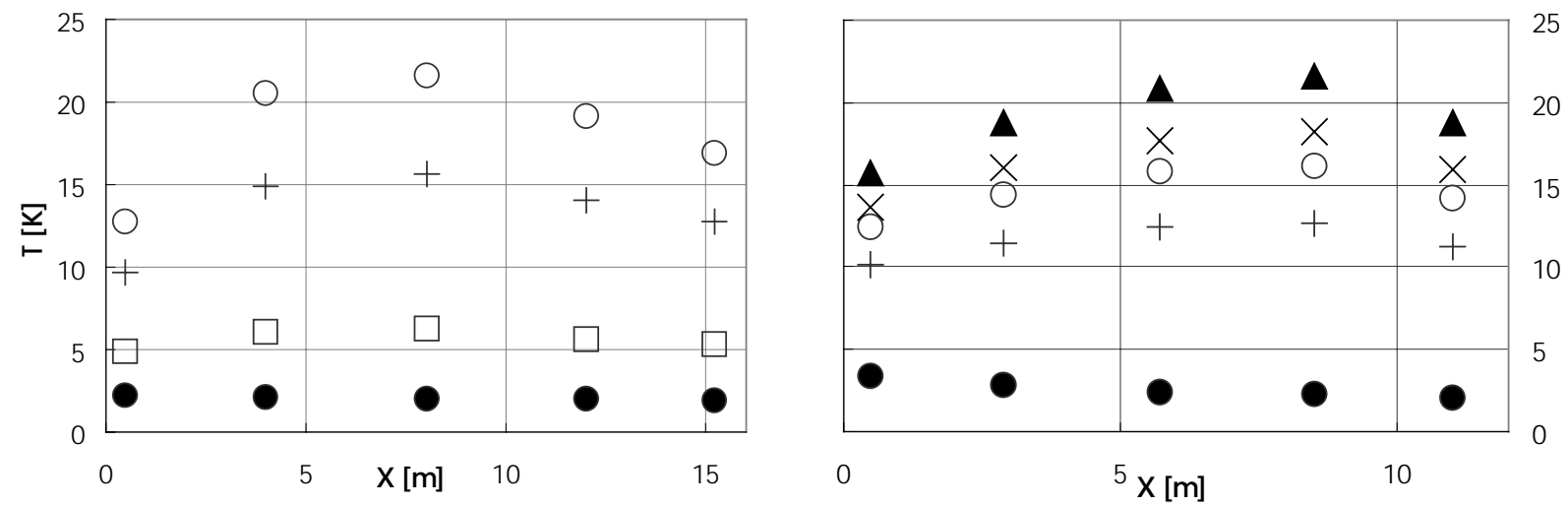

FIGURE 3. Temperature profile along a beam screen without supports (left) and with bronze sliding rings equally spaced by $0.5 \mathrm{~m}$ (right), for increasing applied heat fluxes:
Left:
- $0 \mathrm{~mW} / \mathrm{m}$
$\square 0.32 \mathrm{~mW} / \mathrm{m} \quad+3.2 \mathrm{~mW} / \mathrm{m}$
o $6.3 \mathrm{~mW} / \mathrm{m}$
Right:
- $0 \mathrm{~mW} / \mathrm{m}$
$+3.5 \mathrm{~mW} / \mathrm{m}$
○ $6.1 \mathrm{~mW} / \mathrm{m}$
X $7.8 \mathrm{~mW} / \mathrm{m}$
$\Delta 11.1 \mathrm{~mW} / \mathrm{m}$ 


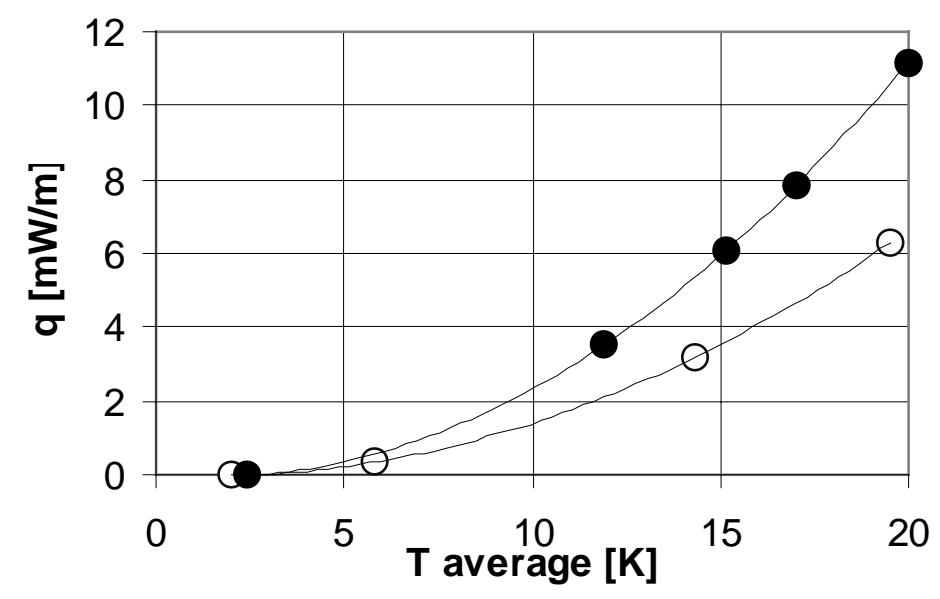

FIGURE 4. Heat flux versus average temperature for a beam screen with $\bullet$ and without $\bigcirc$ supports.

configurations. Boundary effects, as well as, on the left hand graph, a bad attachment of the heater to the beam screen at its extremities, affect the two extreme temperatures.

FIG 4 displays the heating power density versus the average temperature along the beam screen, showing the parabolic dependence which results from the linearity of the heat conductivity of pure metals in this temperature range. In the LHC, the beam screen is supposed to operate between $5 \mathrm{~K}$ and $20 \mathrm{~K}$. Extrapolating from FIG 4 the heat flux for a temperature of $15 \mathrm{~K}$, we obtain $3.5 \mathrm{~mW} / \mathbf{m}$ for a bare beam screen and $\mathbf{5 . 9} \mathbf{~ m W} / \mathbf{m}$ for a beam screen with sliding rings. These values agree with predictions based on electrical resistance measurements at room temperature [9], both for an unsupported beam screen $(2.7 \mathrm{~mW} / \mathrm{m}$ at $15 \mathrm{~K})$ and for a beam screen with bronze sliding rings (heat flux between 0.5 and $5 \mathrm{~mW}$ per support at $15 \mathrm{~K}$ ). It has to be noticed that a calculation based on a uniform temperature of $15 \mathrm{~K}$ is slightly pessimistic with respect to the expected linear temperature profile between $5 \mathrm{~K}$ and $20 \mathrm{~K}$ in the LHC half cell.

With the aim of studying the effects of unforeseen openings in the thermal screening which might occur at joints and connections or voluntarily be produced to pass wires or components, a circular patch of $30 \mathrm{~mm}$ diameter was opened in the thermal screen. A thinwalled tube is attached to the patch, to open and close it from outside the cryostat. Two thin anodised aluminium plates (emissivity $\sim 1$ ) are installed between the thermal screen and the cold-mass, to work as a thermal radiation bolometer and a thermal radiator. High impedance thermalisation and small mass ensure a fast response and a high sensitivity to thermal radiation.

In a first test to simulate a direct opening in the screening towards a warm (vacuum vessel) surface, we verified that the Kapitza heatmeter reacts to thermal radiation emission in the gap between the thermal screen and the cold mass. The heating power applied on the radiator corresponds to an aperture of $65 \mathrm{~cm}^{2}$ radiating at $300 \mathrm{~K}$ in the whole solid angle $(3 \mathrm{~W})$. Both the bolometer and the Kapitza heatmeter react, the latter indicating some 700 $\mathrm{mW}$. In a second test, the patch in the thermal screen is opened. No effect is visible above noise on the losses of the thermal screen nor on the Kapitza heatmeter, while the bolometer reacts by a temperature increase. From its surface opened towards the vacuum vessel, one would expect the patch to radiate approximately $300 \mathrm{~mW}$ in the total solid angle in the gap between the two cold surfaces. Our measurements show promising results with respect to the quantification of the effect of holes in the screening of the LHC cryostat through heatmeters and bolometers, but further tests with realistic openings in the thermal 
screening are required to quantify the unforeseen radiation inleaks and therefore the necessity to equip the LHC cryostat with totally absorptive screens.

\section{CONCLUSIONS}

Thermal performance of MLI for the LHC dipole cryostat was measured on a realscale system, yielding one of the to date lowest values of heat fluxes for an industrial application of MLI. Heat flux between $300 \mathrm{~K}$ and $50 \mathrm{~K}$ does not exceed $0.8 \mathrm{~W} / \mathrm{m}^{2}$, between $50 \mathrm{~K}$ and $2 \mathrm{~K}$ it remains lower than $5 \mathrm{~mW} / \mathrm{m}^{2}$. Successful minimization of fringe effects and parasitic heat loads is obtained at $2 \mathrm{~K}$, whereas possibly a small residual leak persists at $50 \mathrm{~K}$. Degraded vacuum conditions were explored to simulate the case of a leak in the insulation vacuum. The losses to the $1.9 \mathrm{~K}$ bath from a beam screen without supports and with ring supports were measured and found to agree with prediction based on room temperature electrical resistance measurements. Investigation of the influence of openings in the thermal screen on the heat losses at $1.9 \mathrm{~K}$ was carried on both with the Kapitza heatmeter constituting the measuring device at the pseudo cold-mass and with a radiationsensitive bolometer, but further measurements are necessary to be able to draw quantitative conclusions concerning the effect of holes in the LHC cryostat screening.

\section{REFERENCES}

1. Grobner, O. "Overview of the LHC vacuum system", Vacuum 60 no.1-2, 25 (2001).

2. Brunet, J.-C. et al., "Design of the second series $15 \mathrm{~m}$ LHC prototype dipole magnet cryostats", LHCProject-Report-133, Geneva (1998).

3. Camacho, D. et al., "Heat Flow Measurements on LHC Components", Adv. Cryog. Eng. 46A (2000).

4. Castoldi, M. et al., "Thermal Performance of the Supporting System for the Large Hadron Collider (LHC) Superconducting Magnets", Adv. Cryog. Eng. 46A (2000).

5. Nast, T., "Multilayer Insulation Systems", in Handbook of Cryogenic Engineering, edited by J.P.Weisend Jr., Taylor and Francis, 1998 Philadelphia, Chapter 3-4-1.

6. Chaussy, J., et al. "Reduction of evaporation rate by use of metallic adhesive tape", Cryogenics 16, 617 (1976).

7. Lebrun, Ph. et al. "Investigation and Qualification of thermal Insulation Systems between $80 \mathrm{~K}$ and $4.2 \mathrm{~K}$ ", Cryogenics 32, ICMC Supplement, 44 (1992).

8. Conte, R.R. Elements de Cryogenie, Masson et Cie, Paris 1970.

9. Jenninger, B. "Estimation of thermal resistance from room temperature electrical resistance measurements for different LHC beam screen support systems", LHC-PROJ-NOTE 189 (1999) and Heat Loads Working Group, minutes of meeting n.3, in a private communication by B.Jenninger. 